\title{
XLIII. The induction coil
}

\section{Prof. John Trowbridge}

To cite this article: Prof. John Trowbridge (1902) XLIII. The induction coil , Philosophical Magazine Series 6, 3:16, 393-396, DOI: 10.1080/14786440209462779

To link to this article: http://dx.doi.org/10.1080/14786440209462779

$$
\text { 册 Published online: } 15 \text { Apr } 2009 .
$$

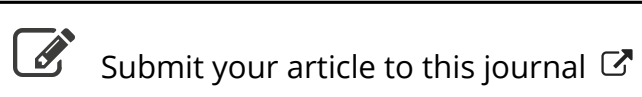

\footnotetext{
Џll Article views: 4
}

Q View related articles $\asymp$ 
of a short tube or the fourth of a longer one, \&c., \&c. This is contrary to what is implied by some writers.

6. The pressures for identical notes on trumpet and cornet are almost the same for any given intensity, but very much less than those for the same notes on the trombone. See Table VI. and Plate VIII. (cf. with Table III. and Plate VII.).

7. The pressures used for loud low notes may exceed those for soft high notes, in some cases even where the notes are an octave apart. See Tables III., IV., V., and VI., also Pls. VII. \& VIII.

8 . The present results as to maximum and minimum pressures are in accord with Dr. Stone's, so far as comparison is possible.

Our thanks are due to Mr. Pickerill for kindly placing his services at our disposal.

University College, Nottingham, August 1901.

XLIII. The Induction Coil. By Prof. John Trowbridge**

T ORD Rayleigh, in a recent article (Philosophical 11 Magazine, Dec. 1901), has shown the significance of the electrostatic capacity between the primary and the secondary of the induction-coil, and has proved that in certain cases a condenser in the primary is of no advantage, and in certain cases may be prejudicial.'

The performance of a powerful coil devised by Mr. Heinze, of Boston, U.S., for me, operated by his liquid interrupter, justifies the points raised by Lord Rayleigh ; and, on account of the importance of the induction-coil in wireless telegraphy, merits I think wider knowledge than it has received.

The dimensions of the coil are as follows :-

Jength of iron of primary coil, 48 inches.

Diameter of " $, \quad, 3 \frac{1}{2}$,

Wound with one layer of no." 6 copper "wire.

The secondary coil consists of 140 coils separated from each other by plates of glass one eighth of an inch thick. Each of these coils is wound with, between 400 and 500 turns, fine wire. The entire resistance of the secondary coil is $246,600 \mathrm{ohms}$.

The secondary is merely inclosed in a box. By unscrewing the cover of this box the sectional coils can be inspected, and any sectional coil can be removed if its insulation breaks down; for the coils are not imbedded in paraffin. It was * Communicated by the Author.

Phil. Mag. S. 6. Vol. 3. No. 16. April 1902. 
found necessary to use glass at least one eighth of an inch thick between the sectional coils, on account of the great electric density developed. Mr. Heinze's experience in this respect corroborates my own. In employing a storagebattery of twenty thousand cells with an electromotive force of forty thousand volts to charge Franklin plates, I have found it necessary to also employ plates of glass one eighth of an inch thick. The great surface-density developed by a powerful rush of current into such condensers to raise them to a difference of potential of even five or ten thousand volts, makes it unsafe to employ glass of less thickness than one eighth of an inch.

When this coil is excited by five storage-cells and is provided with a condenser in the primary, it gives, under the effect of an ordinary vibrating break, a fifteen-inch spark. When, however, the condenser is removed, and the coil is operated by a liquid interrupter shown in fig. 1 , the length of spark is increased to thirty inches and is of astonishing body

The interrupter is contained in a wooden box A (fig. 1), the cover of which swings on hinges and supports all the mechanism. By lifting the cover, the parts can be easily examined. The front of the box consists of a door which, when open, exposes a glass jar $\mathrm{C}$ containing acidulated water, through which the mechanism can be seen. A small motor on the top of the box drives the oscillating mechanism, which consists of a base-casting $\mathrm{E}$ having a bearing and a shaft $F$, upon one end of which is a crank-disk $G$, and at the other end a pulley for receiving its power from the motor. By the rotation of disk $G$ and crank-pin $H$, an up and down movement is imparted to a brass sleeve $I$, which moves up and down upon a vertical spindle $J$ secured to the basecasting $\mathrm{E}$. This sleeve $\mathrm{I}$ has adjustably secured to it a platinum wire $\mathbf{K}$, which projects below the cover $\mathbf{B}$, and moves in and out through a capillary tube closely fitting the wire. This glass tube $L$ is held in a lead electrode $\mathbb{M}$, so constructed as to partly surround and to come very close to the platinum wire when the latter projects through the capillary tube. The electrode $M$, glass tube $L$, and platinum wire $K$ are immersed in the acidulated solution, so that the end of the capillary tube is about an inch below the top of the liquid N. The liquid is a twenty per cent. solution of sulphuric acid. The crank-disk $G$ is made of slate, and has upon its periphery a 90-degree segment of brass $O$ which is connected to the shaft $F$. The segment $O$ bears a certain relation in position to brass sleeve $I$ and depth of platinum 
wire $K$. There is also a movable brush-holder yoke $P$, which has secured to it, but insulated from it, a brush-holder $Q$ and brush $\mathrm{R}$, which rest on disk and segment $\mathrm{O}$ during one-fourth of its revolution.

Fig. 1.

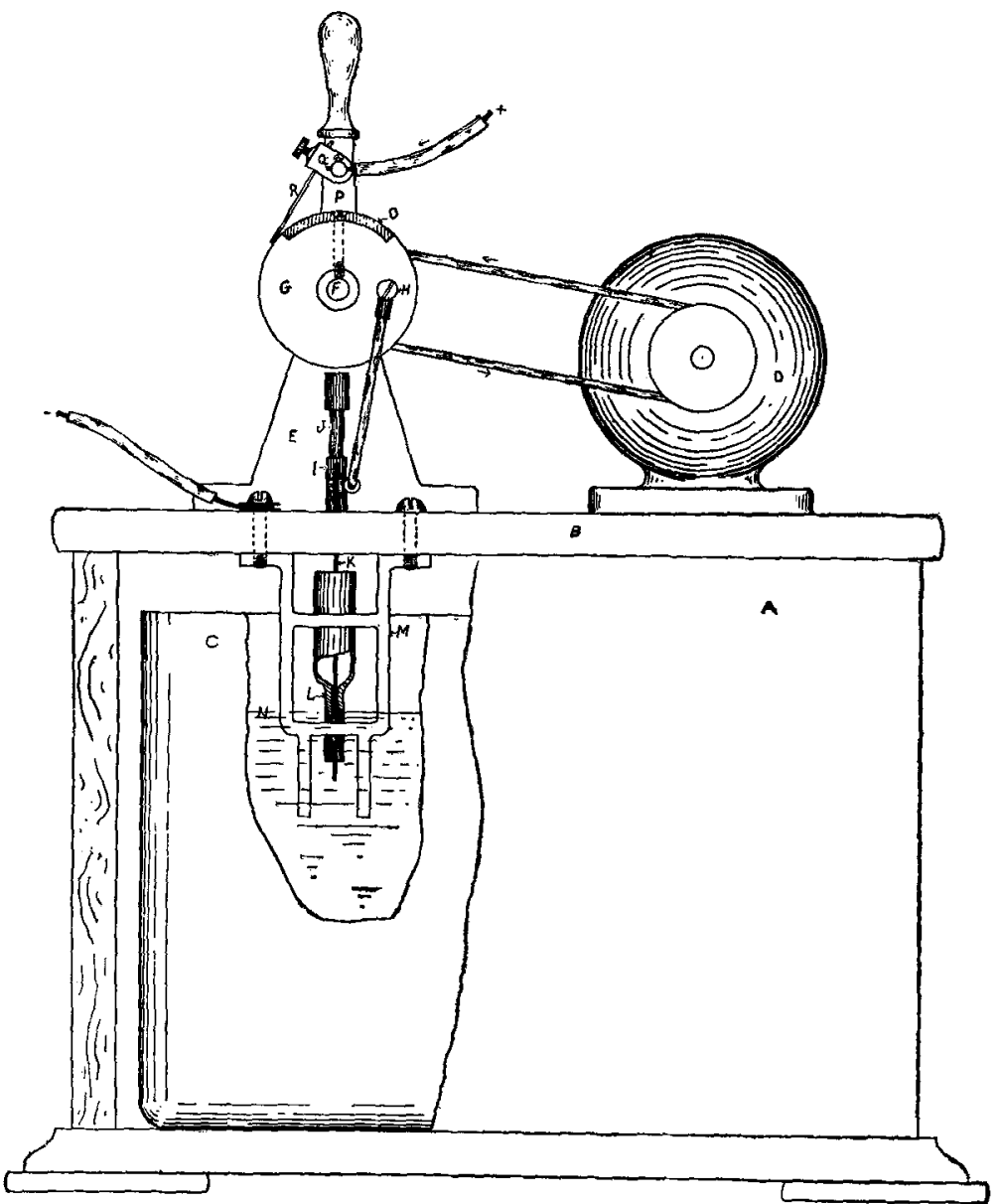

The electric current flows as follows :-The positive wire from the mains (I use a one-hundred-and-ten volt circuit) connects with the brush-holder $P$, and the current flows through the brush $R$ to segment $O$, to shaft $F$, to basecasting $\mathrm{E}$, to vertical spindle $\mathrm{J}$, to brass sleeve $\mathrm{I}$, to platinum wire $K$; and when the wire is immersed in the liquid $N$, the 
current flows through it to the lead electrode $M$, to one end of the primary of the coil, and out by the other end to the negative wire of the mains. By the movement of the brush one can regulate the amount of current passing through the primary.

The number of interruptions per minute can be changed from sixty to five thousand by varying the speed of the motor. The regulating handle of the motor will change the spark-length of the coil from zero to thirty inches and will also vary the quantity of the discharge.

The momentary rush of current through the primary coil is probably very great, although the ammeter in the primary circuit indicates not more than 5 or 10 amperes. I have found it impossible to produce a spark in air longer than seven feet by means of a storage-battery and a Planté transformer. I imagine that a large coil built on the above principle and actuated by very powerful commercial currents could produce sparks much longer than seven feet. Dynamos are now built of a size far exceeding what was once thought possible. The needs of wireless telegraphy may demand a corresponding increase in the size of induction-coils; and the coil of the type I have described, without a condenser and with a liquid break, seems to be the type for the future, if powerful discharges are desired. The mechanical break and the primary condenser must be relegated to the historical physical cabinet.

Jefferson Physical Laboratory,

Harvard University, Cambridge, U.S.

XLIV. A suspected case of the Electrical Resonance of Minute Metal Particles for Light-wares. A New Type of Absorption. By R. W. Woon, Professor of Experimental Physics in the Johns Hopkins University*.

CERTAIN experiments on which I have been engaged of $\mathcal{C}$ late have led me to believe that I have found a new type of light absorption, which it may be possible to refer to the electrical resonanee of small metallic particles for waves of light. The experiments of Garbasso and Aschkinass have shown that a plate of glass covered with uniformly arranged strips of tinfoil of equal size, which serve as resonators, shows the phenomenon of selective transmission and reflexion for electromagnetic waves of different wave-lengths. In other words, a plate of this description exbibits the electrical analogy of surface-colour. I have succeeded in producing

* Communicated by the Physical Society : read March 14, 1902. 